\title{
STUDY OF PATIENTS' ACCEPTABILITY AND ATTITUDE TOWARDS THE UNDERGRADUATE MEDICAL STUDENTS IN A TERTIARY CARE TEACHING HOSPITAL OF EASTERN INDIA
}

\author{
Bandyopadhyay Debasis* \\ Associate Professor, Department Of Pharmacology, Burdwan Medical College, Burdwan West Bengal, INDIA-713104 \\ Email Id* of the Corresponding Author: drdebasisbandyopadhyay@yahoo.in, Mobile No.09474786492
}

\begin{abstract}
Background: Patients have always been part of medical education. The patients' co-operation with the undergraduate medical students is vital in clinical education. Patient contact is an integral component of medical education, training and assessment. It provides students and doctors with an opportunity to learn and to develop their professional skills, attitudes and identity. Patients can also benefit from involvement in teaching and training, by increasing their own knowledge, and indirectly through improved training of the medical workforce. Recent reforms of medical education now use more structured and extensive patient contact. Patients should be actively involved in the development, review and implementation of Medical curriculum. But lack of experience of the large number students may evoke negative attitude and acceptability of patients which may sometimes adversely affect the clinical teaching environment. Lots of studies conducted on this area in the different part of the world with varying results with different cultural patients with socio-demographic variation. In this area there was need of more studies especially at this part of the world, Burdwan Medical College, India, where there was no such study conducted before. Objective: In this study my objective was to explore the attitude \& acceptability of the undergraduate medical students by the patients in a tertiary care teaching hospital of eastern India. Methods: This study was conducted among 560 patients in OPD \& inpatients in Burdwan Medical College, Burdwan , India, from March 2012- June 2012, using predesigned structured questionnaires. Results: Among 560 patients 545 patients responded. Male patients were $54.678 \%$ \& female were $45.32 \%$. Hindu patients were $37.064 \%(\mathrm{n}=202)$ and Muslim patients were $62.935 \%$ ( $\mathrm{n}=343)$. Higher acceptance of both male\& female undergraduate medical students at the rate of $86.972 \%(\mathrm{n}=474)$ by the patients when there was medical examination with the presence of doctors. Whereas only $30.09 \%(n=164)$ acceptance of both male \& female students by the patients when there was no doctors. In general there was higher acceptance of both sexes' students by the patients when there was no direct contact with the patients, e.g. taking history of illness, presenting at the OPD clinic, reading the patients file etc. $69.908 \%(n=381)$ of patients felt comfortable with the presence of medical students, while $79.266 \%(n=432)$ of patients gave favorable opinion regarding the improvement of the quality of health care with the presence of undergraduate medical students. Conclusion: Though a large number of patients did not accept the students without the presence doctor, but majority of the patients showed overall positive attitude towards the involvement of medical students.

Key Words: Medical Students, Medical Education, Patients' acceptability, OPD Clinic.
\end{abstract}

\section{INTRODUCTION}

Patient contact is at the heart of Medical Education ${ }^{1}$. One of the primary benefits of patient involvement in medical education is the improvement of training of the medical students, resulting in improved healthcare for the whole population. Patients will be benefited also, for example, as students gain experience of interacting with patients and develop sensitivities needed for shared decision-making, which is an increasingly prominent and expected aspect of healthcare ${ }^{2}$.Hence the importance of patients' involvement in medical education and particularly in having more active roles, such as acting as a teacher ${ }^{3}$. A number of studies in a variety of settings have shown that patients are willing to participate in the education of medical students and that satisfaction is generally positive after participating in undergraduate medical education ${ }^{4,5}$. Patients who participate and interact in medical education have reported a number of perceived benefits, including being able to increase their own knowledge; share their knowledge and expertise with the learner; and gain satisfaction and enjoyment from the system 6,7 . Patients are also used in undergraduate examinations and studies have shown that patients generally enjoy participating in examinations and are willing to contribute ${ }^{8}$. In cases when patients may not perceive a significant benefit to themselves, an altruistic notion of a greater social benefit, rather than having an obligation, can motivate patients to participate in medical education ${ }^{9,10}$. While the majority of feedback from patients is generally positive in regards to medical student participation; there may still be the risk of patients having a negative experience or experiencing an adverse effect. Different studies conducted in the part of the world with varying results on the specific demographic profile of patients $11,12,13,14$. In this aspect this study was needed in this geographic area with different socio-economic demographic profile of patients. In this study I explored the attitude \& acceptability of the undergraduate medical students by the patients on different socio demographic parameters of the patients and I also explored where there was any effect of the student's gender on the acceptability by the patients, in Burdwan Medical College, West Bengal, India, where in the past there was no such study conducted. In this background I conducted this study myself in my Institute.

\section{MATERIALS AND METHODS}

Participants: In this study 560 patients were being approached. The entire patients were randomly selected from the out-patient-department and some admitted patient, in the Burdwan Medical College\& Hospital, West Bengal, India.

Ethical consideration: This study was approved by the institutional ethical committee and valid written informed consent was taken from each students.

Study duration: The duration of the study was only four months from March-June 2012.

Study design: My study was prospective, open level, unblinded, uncontrolled and cross-sectional study that relied on face-to-face interviews. 
Methodology: Pre validated, Reliable, standardized, predesigned 10 points based structured questionnaires (Table No. 1) were distributed among the randomly selected patients to explore the reaction of the patients. Besides these questionnaires a separate set of questionnaires regarding the socio demographic characteristic which were related to age, nationality, gender, marital status, religion, education, occupation and current family income. The patients were asked to answer the questionnaires in unbiased \& truthful way and not to produce their identity. All the questionnaires were approved by my institutional ethical committee.

Validity, Reliability and Standardizations of the questionnaires was determined through reviewing the

Table No. 1: Showing reliable, validated, standardized, 10 point questionnaires regarding the exploration of the patients' reaction towards the undergraduate medical students in Burdwan Medical College, West Bengal, India.

\begin{tabular}{|c|c|}
\hline Question No. & Questionnaires \\
\hline Question No. 1 & Whether you permit examination by the undergraduate medical students, in the presence of doctor. \\
\hline Question No. 2 & Whether you permit examination by the undergraduate medical students, without the presence of doctor. \\
\hline Question No. 3 & $\begin{array}{c}\text { Whether you permit the medical students to take personal details \& medical history from you, with the } \\
\text { presence of a doctor. }\end{array}$ \\
\hline Question No. 4 & $\begin{array}{c}\text { Whether you permit the medical students to take personal details \& medical history from you, without the } \\
\text { presence of a doctor. }\end{array}$ \\
\hline Question No. 5 & $\begin{array}{c}\text { When you are in the diagnostic procedure such as insertion of catheter, endoscopy, etc, Whether you allow } \\
\text { medical students to be present }\end{array}$ \\
\hline Question No.6 & Whether you permit diagnostic procedures by the medical students \\
\hline Question No. 7 & Whether you allow undergraduate medical students to be present, while your doctor examining you. \\
\hline Question No. 8 & $\begin{array}{c}\text { When you were having surgery, Whether you permit undergraduate medical students to be present in the } \\
\text { operation room. }\end{array}$ \\
\hline Question No. 9 & Whether you allow the undergraduate medical students to read your medical file \\
\hline Question No. 10 & $\begin{array}{l}\text { When you were having a consultation with your doctor, Whether you permit undergraduate medical } \\
\text { students to be present in the OPD clinic }\end{array}$ \\
\hline
\end{tabular}

\section{RESULTS AND ANALYSIS}

In this study 560 patients were being approached. 545 patients were responded. Responder rate was $97.321 \%$. Male patients were $54.678 \%$ \& female were $45.32 \%$. The patients mean age was $39.19 \pm 11.18$ years (range 12-75). literature and obtaining the experts' theories, and its reliability was measured by Cronbach's Alpha Reliability Coefficient for Likert-type Scales. The coefficient alpha was $=0.805$, that demonstrated a good reliability of the questionnaires 15,16 ,

Statistical analysis: All the collected data were analyzed with the descriptive statistics by using the Statistical Package for the Social Science (SPSS) ver-16 in Windows-7. The chisquare test was applied to detect any significant difference of recation between the responses of different questionnaires. A value of $p<0.05$ was considered statistically significant. But frequency analysis and content analysis of the responders, done by manually.

\section{Table No. 2: Showing the socio demographic profile of the patients $(n=545)$.}

\begin{tabular}{|c|c|c|}
\hline Table No. 2 & Number of patients & $\%$ \\
\hline Age, $12-60$ years & 305 & $55.963 \%$ \\
\hline Age, $61-75$ years & 240 & $44.036 \%$ \\
\hline \multicolumn{3}{|l|}{ Mean Age $39.19 \pm 11.18$ years } \\
\hline Nationality: Indian & 545 & $100 \%$ \\
\hline Gender: Male & 298 & $54.678 \%$ \\
\hline : Female & 247 & $45.321 \%$ \\
\hline Marital Status: Married & 311 & $57.064 \%$ \\
\hline : Unmarried & 234 & $42.935 \%$ \\
\hline Religion: Hindu & 202 & $37.064 \%$ \\
\hline : Muslim & 343 & $62.935 \%$ \\
\hline Educational Status :Below the Secondary Education & 164 & $30.091 \%$ \\
\hline At the level of Secondary Education & 180 & $33.027 \%$ \\
\hline At the level of Higher Secondary Education & 131 & $24.036 \%$ \\
\hline At the level of University Education & 70 & $12.844 \%$ \\
\hline Occupation: Unemployed & 383 & $70.275 \%$ \\
\hline : Employed & 162 & $29.724 \%$ \\
\hline Family Income: < Rs. 5000 per month & 412 & $75.596 \%$ \\
\hline :> Rs. 5000 per month & 133 & $24.403 \%$ \\
\hline
\end{tabular}


$86.972 \%$ of $(n=474)$ of the responded patients permit both male and female undergraduate medical students to conduct examination, with the presence of a doctor, while only $30.09 \%$ of the patients allow examination without the presence of doctor. Details reactions of the patients are shown in the Table No. 3.

Table No. 3: Showing the details reaction of the Patients (Acceptability Responses) towards the Undergraduate Medical Students in the Burdwan Medical College, West Bengal, India.

\begin{tabular}{|c|c|c|c|c|c|c|c|c|}
\hline \multirow{2}{*}{$\begin{array}{l}\text { Table No. } 3 \\
\text { Question No. }\end{array}$} & \multicolumn{2}{|c|}{$\begin{array}{c}\text { Allow only } \\
\text { Male }\end{array}$} & \multicolumn{2}{|c|}{$\begin{array}{c}\text { Allow only } \\
\text { Female }\end{array}$} & \multicolumn{2}{|c|}{$\begin{array}{c}\text { Allow both Male } \\
\text { \&Female }\end{array}$} & \multicolumn{2}{|c|}{ Allow neither Male nor Female } \\
\hline & No & $\%$ & No. & $\%$ & No. & $\%$ & No. & $\%$ \\
\hline Question No. 1 & 22 & $4.04 \%$ & 17 & $3.12 \%$ & 474 & $86.97 \%$ & 32 & $5.87 \%$ \\
\hline Question No. 2 & 23 & $4.22 \%$ & 15 & $2.75 \%$ & 164 & $30.09 \%$ & 343 & $62.94 \%$ \\
\hline Question No. 3 & 12 & $2.20 \%$ & 10 & $1.83 \%$ & 482 & $88.44 \%$ & 41 & $7.52 \%$ \\
\hline Question No. 4 & 25 & $4.59 \%$ & 24 & $4.40 \%$ & 275 & $50.46 \%$ & 221 & $40.55 \%$ \\
\hline Question No.5 & 32 & $5.87 \%$ & 31 & $5.69 \%$ & 328 & $60.18 \%$ & 154 & $28.26 \%$ \\
\hline Question No. 6 & 8 & $1.47 \%$ & 20 & $3.67 \%$ & 163 & $29.91 \%$ & 354 & $64.95 \%$ \\
\hline Question No.7 & 36 & $6.61 \%$ & 15 & $2.75 \%$ & 336 & $61.65 \%$ & 158 & $28.99 \%$ \\
\hline Question No. 8 & 40 & $7.34 \%$ & 12 & $2.20 \%$ & 342 & $62.75 \%$ & 151 & $27.71 \%$ \\
\hline Question No.9 & 19 & $3.49 \%$ & 16 & $2.94 \%$ & 481 & $88.26 \%$ & 29 & $5.32 \%$ \\
\hline Question No. 10 & 46 & $8.44 \%$ & 65 & $11.93 \%$ & 380 & $69.72 \%$ & 54 & $9.91 \%$ \\
\hline
\end{tabular}

Figure No. 1: Showing the details reaction( Acceptability Responses) of the Patients $(\mathrm{n}=545)$ towards the both Male\& Female, Undergraduate Medical Students,Burdwan Medical College,West Bengal,India

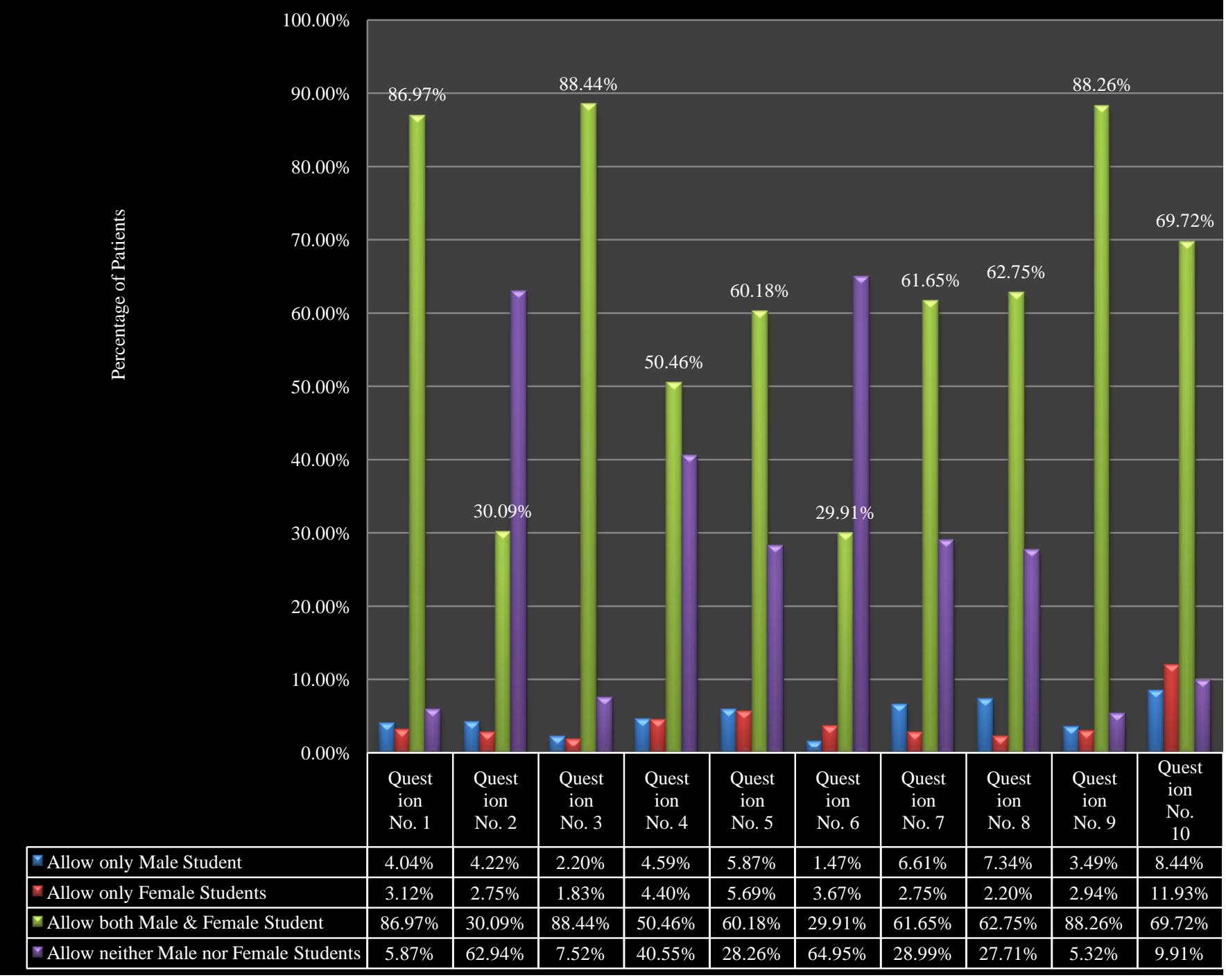


Regarding history taking $88.44 \%$ of the patients permit the medical students to take personal details \& medical history but with the presence of a doctor and only about half of the patients allow without the presence of a doctor. About $60 \%$ of the responded patients allow the both male \& female undergraduate medical students to present at the time of diagnostic procedure. But only $29.908 \%$ of the responded patients permit diagnostic procedure by the both male and female undergraduate medical students, while more than majority of the patients $(n=354)$ did not allow neither male nor female students for making diagnostic procedure. Although patients showed a high refusal $(62.935 \%, n=343)$ in allowing both genders of medical students to examine them without the presence of a doctor, the majority of the patients $(61.651 \%, n=336)$ allowed both genders of students to be present while the doctor examining them. When the patients were asked about their acceptance regarding the presence of medical students in the operation theatre if their condition required a surgical intervention, $27.706 \%(n=151)$ of them refused both male and female students to be present, while $62.752 \%(n=342)$ of patients allowed \& agreed on both genders of students to be present. Over $88 \%(n=481)$ of the patients permit both male and female students to read their medical file. Also about $70 \%$ of the responded patients permit both genders of medical students to present in the outpatient department (OPD) clinic and only negligible amount $(9.908 \%)$ of patients did not allow neither male nor female students. The acceptance of the patients was closely associated with some socio demographic parameters when statistically analyzed by the chi-square test.

The details acceptability responses of the responded patients towards the male, female and both genders are distributed in the Figure No. 1.

The statistical analyses by the chi-square test showed that some socio demographic parameters such as patient's gender, occupation, income, education and marital status were statistically highly significantly associated $(\mathrm{p}<0.05)$ with acceptability by the patients. The details variations of the responses according to the socio demographic parameters are shown in the Table No. 4.

Table No. 4: Showing the reaction (acceptability responses) of the patients towards the medical students according to the socio demographic parameters.

\begin{tabular}{|c|c|c|c|c|c|c|c|c|}
\hline Table No. 4 & \multicolumn{2}{|c|}{$\begin{array}{l}\text { Allow only Male } \\
\text { students }\end{array}$} & \multicolumn{2}{|c|}{$\begin{array}{l}\text { Allow only } \\
\text { Female students }\end{array}$} & \multicolumn{2}{|c|}{$\begin{array}{l}\text { Allow both Male and } \\
\text { Female students }\end{array}$} & \multicolumn{2}{|c|}{$\begin{array}{l}\text { Allow neither Male } \\
\text { nor Female }\end{array}$} \\
\hline $\begin{array}{l}\text { Socio Demographic } \\
\text { Parameters }\end{array}$ & No. & $\%$ & No & $\%$ & No. & $\%$ & No. & $\%$ \\
\hline Age: $12-60$ years & 15 & $4.91 \%$ & 25 & $8.20 \%$ & 206 & $67.54 \%$ & 59 & $19.34 \%$ \\
\hline Age: $61-75$ years & 12 & $5.00 \%$ & 20 & $8.33 \%$ & 190 & $79.16 \%$ & 18 & $7.50 \%$ \\
\hline Genders: Male & 20 & $6.71 \%$ & 12 & $4.02 \%$ & 240 & $80.53 \%$ & 26 & $8.72 \%$ \\
\hline Genders: Female & 3 & $1.21 \%$ & 8 & $3.23 \%$ & 232 & $93.92 \%$ & 4 & $1.62 \%$ \\
\hline $\begin{array}{l}\text { Marital Status: } \\
\text { Married }\end{array}$ & 15 & $4.82 \%$ & 26 & $8.36 \%$ & 239 & $76.84 \%$ & 31 & $9.36 \%$ \\
\hline Unmarried & 23 & $9.82 \%$ & 30 & $12.82 \%$ & 158 & $67.52 \%$ & 23 & $9.82 \%$ \\
\hline Religion: Hindu & 11 & $5.44 \%$ & 12 & $5.94 \%$ & 159 & $78.71 \%$ & 20 & $9.90 \%$ \\
\hline Muslim & 20 & $5.83 \%$ & 29 & $8.45 \%$ & 252 & $73.47 \%$ & 42 & $12.24 \%$ \\
\hline $\begin{array}{l}\text { Occupation: } \\
\text { Employed }\end{array}$ & 7 & $4.32 \%$ & 8 & $4.94 \%$ & 132 & $81.48 \%$ & 15 & $9.25 \%$ \\
\hline Unemployed & 21 & $5.48 \%$ & 29 & $7.57 \%$ & 262 & $68.40 \%$ & 71 & $18.54 \%$ \\
\hline $\begin{array}{l}\text { Family Income: < Rs. } \\
5000 \text { per month }\end{array}$ & 28 & $6.79 \%$ & 40 & $9.71 \%$ & 265 & $64.32 \%$ & 79 & $19.17 \%$ \\
\hline $\begin{array}{l}\text { Family Income: > Rs. } \\
5000 \text { per month }\end{array}$ & 4 & $3.01 \%$ & 6 & $4.51 \%$ & 109 & $81.95 \%$ & 14 & $10.53 \%$ \\
\hline
\end{tabular}

In general acceptance rate of Muslim, unmarried patients, and patient with poor income group was less than that of the Hindu, married patients. Refusal rate among male patients were more than that of the female patients which was similar like that of unemployed poor patients. While $69.908 \%(n=381)$ of patients felt comfortable with the presence of medical students, and $79.266 \%(n=432)$ of patients gave favorable opinion regarding the improvement of the quality of health care with the presence of undergraduate medical students.

\section{DISCUSSION}

Patient contact lies at the heart of medical education. Traditionally, patients have had a passive role; they were useful in terms of what the student could learn from them

but not usually invited to be a fully informed and autonomous partner. Now, as greater emphasis is given to providing patient-centered care, valuing the partnership between patients and doctors, sharing decision-making and promoting self-care; there has been a corresponding shift towards patient-centered learning within medicine. This provides considerable benefits for learners and patients alike $^{18}$.

Patient interaction in undergraduate education offers students a valuable early insight into the day-to-day role of a doctor and the patient perspective on specific conditions. It also encourages empathy and understanding; motivates students to learn; can encourage the student to gain in confidence; and gives them a greater knowledge of professional roles and responsibilities and the illnesses SN: 2250-1177
CODEN (USA): JDDTAO 
they need to recognize and treat ${ }^{19}$. Students are able to develop their professional skills, attitudes and identity, through both direct interaction and from the observation of their teachers and peers ${ }^{20}$. A community based setting in undergraduate education, for example, is beneficial as it allows students to experience a more personal relationship with patients, to recognize the importance of treating people instead of 'a disease' and how the social environment has a significant impact on health and healthcare ${ }^{21}$.

Expectations of the roles of patients in medical education are changing as greater consideration is given to what patients themselves can contribute to the educational process and what the benefits (or harms) are to them in doing so. Their roles are starting to develop beyond involvement in training and assessment, to contributing to the way future doctors are educated, such as having a formal role in teaching ${ }^{18}$. Patients have tended in the past to have a passive role in medical education; often they were seen simply as a 'disease' or 'an interesting case', rather than being an autonomous and informed partner in healthcare or education. By only having a focus on the clinical and scientific aspects of a disease or condition; the student, trainee or doctor would often miss the patient's emotional and personal responses, as well as the patient's self-knowledge and knowledge of their disease ${ }^{8}$. With the

\section{REFERENCES}

[1] General Medical Council. Core education outcomes, GMC education committee position statement. 2006. Available at www.gmc-uk.org

[2] Coleman K and Murray E. Patient's views and feelings on the community-based teaching of undergraduate medical students: a qualitative study. Family Practice. 2002; 19 (2): 183-8.

[3] Wykurz G and Kelly D. Developing the role of patients as teachers: literature review.2002; BMJ 325: 818-21.

[4] Jones S, Oswald N, Date J et al. Attitudes of patients to medical student participation: general practice consultations on the Cambridge Community-Based Clinical Course. Medical Education. 1996; 30:14-7.

[5] Benson J, Quince T, Hibble A et al.Impact on patients of expanded, general practice based, student teaching: observational and qualitative study. BMJ, 2005; 331: 89.

[6] Jackson A, Blaxter L and Lewando-Hundt G. Participating in medical education: views of patients and carers living in deprived communities. Medical Education.2003; 37: 532-8.

[7] Sharma T and Katona CLE. Patients' perceptions of medical finals. Medical Teacher.1994; 16: 61-70.

[8] Hasman A, Coulter A and Askham J. Education for partnership developments for medical education. 2006; Oxford: Picker Institute Europe.

[9] Scottish Deans' Medical Curriculum Group: Learning outcomes for the medical undergraduate in Scotland: a foundation for competent and reflective practitioners, 32007 Available in: http://www.scottishdoctor.org/resources/ scottishdoctor3.doc

[10] Lowe M, Kerridge I, McPhee J et al. Do patients have an obligation to participate in student teaching. Medical Education.2008; 42: 237-241.

[11] Howe, A. Patient-centered medicine through student-centered teaching - a student perspective on the key impacts of community- shift in emphasis towards patient-centered care, patients also have a more prominent role in education and training. There are potential barriers to this patient-centered focus, however, including the existing medical culture, a lack of interest in the topic, curricula pressures, service pressures, insufficient evidence of effectiveness and lack of an effective mechanism to spread good practice. There are also a number of challenges to the involvement of patients in the various stages of medical education including organizational and practical considerations, as well as matters relating specifically to the patient including consent and confidentiality ${ }^{8}$. There were many studies conducted on this area ${ }^{11,12,13,14}$, with different results. The results of my study tally with that.

\section{CONCLUSION}

Though majority of patients felt comfortable with the presence of medical students, and gave favorable opinion regarding the improvement of the quality of health care with the presence of undergraduate medical students in my institute and accept them but a substantial portion of patients having negative attitude. So medical students need to be able to interact effectively with patients from a diverse range of backgrounds of patients and with differing needs. Further research should be undertaken into the factors that affect patient attitudes to, and acceptance of, medical student participation.

based learning in undergraduate medical education. Med. Educ. 2001;35: 666-72.

[12] Walters K, Buszewicz M, Russell J et al. Teaching as therapy: cross sectional and qualitative evaluation of patients' experiences of undergraduate psychiatry teaching in the community. BMJ.2003; 326: 740-5.

[13] Choudhury TR, Moosa AA, Cushing A, Bestwick J: Patients' attitudes towards the presence of medical students during consultations. Med Teach 2006, 28:e198-e203.

[14] O’Malley G, Omori DM, Landry FJ et al. A prospective study to assess the effect of ambulatory teaching on patient satisfaction. Academic Medicine.1997; 72:1015-7.

[15] Petra MB, Trisha G. Hands-on guide to questionnaire research. Selecting, designing and developing your questionnaire. BMJ, $29^{\text {th }}$ May, 2004; 328:1312-15.

[16] Sapsford R. Survey research. London: Sage, 1999.

[17] Howitt D and Cramer D. First steps in research and statistics. London: Routledge, 2000.

[18] Littlewood S, Ypinazar V, Margolis SA et al. Early practical experience and the social responsiveness of clinical education: systematic review. BMJ.2005; 331: 387-91.

[19] Howe A. Ally, advocate, authority: strengthening the patient voice in medical education. The Clinical Teacher4.2007: 170-74.

[20] Howe A, Dagley V, Hopayian K et al. Patient contact in the first year of basic medical training - Feasible, educational, acceptable? Medical Teacher.2007; 29: 237-45.

[21] Howe A. Patient-centred medicine through student-centred teaching - a student perspective on the key impacts of communitybased learning in undergraduate medical education. Medical Education.2001; 35: 666-72. 